\title{
How to Retain Eyewear Sales and Boost Revenue
}

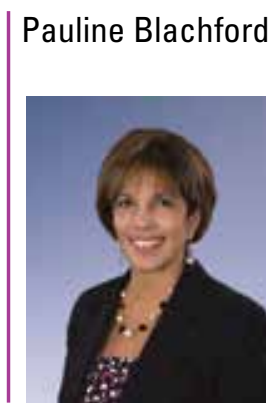

\begin{abstract}
Pauline Blachford consults optometrists on how to reduce unbooked appointments, increase eyewear sales, and improve employee productivity. She has abundant experience in the eye health industry, including 17 years at White Rock Optometry in BC. Pauline frequently presents at optometry conferences and is a regular columnist for the CJO. For more information, visit paulineblachford.com.
\end{abstract}

$\mathrm{Y}$ ou and your team know your patients' unique eyewear needs, and have the expertise to provide them with the perfect product. This alone, however, isn't necessarily enough to ensure your patients buy their glasses and contact lenses from you, their trusted optometry team.

Whether they're chasing affordability or a specific style, one out of three eyeglass patients fill their prescriptions elsewhere. ${ }^{1}$ In fact, in the U.S. market, the top four companies in the eyewear industry are strictly retailers, and collectively account for $45 \%$ of the market's revenue. ${ }^{2}$ That figure doesn't even include Walmart, Costco or 1-800 Contacts.

Despite being a highly competitive and increasingly concentrated market, eyewear sales are worth the bother, and on average, anywhere from $40-60 \%$ of an independent optometrist's bottom line. An American optometry practice with an annual gross revenue of $\$ 750,000$ sees about $\$ 160,000$ of potential eyewear revenue walk out the door each year. ${ }^{3}$

To retain current eyewear sales and reclaim some of the business that goes elsewhere, here are several strategies small and medium-sized practices can implement to maximize their strengths and boost their bottom line.

\section{Trust and personality}

Loyal customers buy more, buy more frequently and buy higher-end products than any other type of customer. ${ }^{4}$ In short, it's worth it to your practice to invest in strengthening your patient relationships.

Research suggests that patient loyalty is developed through continuity of care, and a greater personalization of service. ${ }^{5}$ When customers had the opportunity to create a positive, emotional bond with service representatives in the retailbanking sector, $85 \%$ of customers purchased or invested more. ${ }^{6}$ And generally speaking, $70 \%$ of buying experiences are based on how a customer feels they are being treated, ${ }^{7}$ and as many as $81 \%$ of customers would pay extra for better service. ${ }^{8}$

One way to provide continuity of care and personalized service is to extend the excellent eye care you deliver in the examination room to the level of customer service you provide in the optical department. I wrote about the impact that telephone recalling has on increasing trust in a past $C J O$ issue $^{8}$ and, obviously, a great handoff after the eye exam is key. Some optometrists I work with have their optician join them in the exam room to discuss the type of lenses being prescribed to the patient. Others introduce the patient to their optician after an exam, and reiterate their eyewear recommendations. Both methods show the patient you will go over-and-above to ensure they get the right eyewear for their unique needs. They also begin to expand doctor-patient trust and loyalty to include your optician.

\section{Patient convenience}

Research shows that purchasing directly from their optometrist right after an eye exam is a convenience patients prefer, 10 and smart recalling is the most effective way to ensure a patient comes to your clinic ready to buy.

When booking patients, have your recaller invite them to set aside at least an hour for their visit to your clinic. Clients often underestimate how long it takes to receive great service and have to rush out the door to get to their next appointment before having the chance to shop for their eyewear.

You can also have your recaller ask clients to bring in all their eyewear, including glasses, contact lenses and sunglasses. This small act may uncover that the patient has lost their glasses, or are out of contact lenses. By making the appropriate notes, your recaller can ensure all optometry staff are prepared 
to meet each patient's eyewear needs. It also makes patients feel more prepared to make a purchase when they can compare what they will be getting to what they had.

Following the exam, a few small initiatives can help further increase convenience. For example, have your staff encourage your contact lens wearers to purchase a year's supply of lenses and solution. Give them a discount if they do so. This won't have a dramatic influence on your profits, but it will establish that your clinic is a one-stop shop for all your clients' eyewear needs. Also, have your staff complete and mail your clients' insurance rebate forms.

\section{Increasing revenue per patient and closing the sale}

From LensCrafters to Walmart, retailers in the eyewear industry are in the business of selling. They are experts in upselling customers and pros at attracting new ones with deals. When independent optometry practices pair their eye care services with effective sales strategies, they too can reap the rewards enjoyed by the bigger eyewear chains.

The opticians I meet when I'm consulting and speaking at conferences always amaze me with their eyewear knowledge and technical skills. But they often confide that they aren't comfortable selling the products. The research confirms this. According to a report prepared by the Review of Optometric Business, most optometrists capture only a portion of the existing eyewear and contact lens demand within their patient bases. ${ }^{11}$

It isn't enough to merely explain to patients the features and benefits of the lenses you offer, and at worst, inundating patients with information may turn them off a sale. Having your optician complement their eyewear knowledge with sales training will give them the skills to close a sale, including how to ask the right questions, and how to listen to a patient's needs. Plus, the opticians I've trained in sales strategies always report feeling more confident, which is half the battle when it comes to sales.

Every practice is unique, but when independent practices exploit their strengths - particularly when it comes to providing excellent service - optometrists can not only avoid losing sales to bigger retailers, but they can boost their eyewear sales across the board.

To learn how you can develop an effective business strategy to increase eyewear sales or for sales training for your opticians, please email me at info@paulineblachford.com or visit paulineblachford.com.

\section{References}

1. Review of Optometric Business. (2013). Challenges and Opportunities in the Future of Independent Optometry.

2. IBISWorld. (2015). Eye Glasses \& Contact Lens Stores Market Research Report. Retrieved from http://www.ibisworld.com/industry/default.aspx?indid=1056.

3. Supra note 1 at 8 .

4. Ibid at 6 .

5. Ibid.

6. Beaujean, M. Davidson, J. \& Madge, S. (2006). The 'moment of truth' in customer service. McKinsey Quarterly. Retrieved from http://www.mckinsey. com/insights/organization/the_moment_of_truth_in_customer_service.

7. Ibid.

8. Oracle. (2012). Why Customer 'Satisfaction' is No Longer Good Enough. Retrieved from http://www.oracle.com/us/dm/ora-rightnowwhitepaper-12-10719-1882784.pdf.

9. Blachford, Pauline (2013). Take Action to Ensure Client Loyalty. Canadian Journal of Optometry, 75(4), 14.

10. Gailmard, N. Pricing Optical Products to Maximize Gross Profit. Review of Optometric Business. Retrieved from http://www.reviewob.com/Data/ Sites/1/webinarwhitepaper_ccpricing_lr.pdf.

11. Supra note 1 at 11 .

\section{CLASSIFIED}

\section{Practice for Sale}

A non-dispensing medical practice is available for sale in Toronto close to all TTC transit options, in a wellappointed medical building, with parking. Includes VF, OCT, HRT, photos and a robust electronic medical records system with $10,000+$ active patients. Four fully-equipped examination lanes, 4.5 years remain on existing lease, well-trained and enthusiastic staff. Glaucoma management experience and prescribing ability is essential. The owner is willing to continue part-time to assist in the transition.

Interested applicants are requested to send their CV and letters of interest to torontoeyedoc@icloud.com, and suitable applicants will be contacted. 